\title{
A RARE CASE REPORT OF SQUAMOUS CELL CARCINOMA OF URETHRA ARISING FROM SUBSTITUTED PENILE SKIN FLAP WITH BALANITIS XEROTICA OBLITERANS
}

Rana Pratap Singh ${ }^{1}$, Khalid Mahmood², Kamlesh Gunjan ${ }^{3}$, Anshul Garg $^{4}$, Rajesh Tiwari ${ }^{5}$

${ }^{1}$ Student, Department of Urology, IGIMS.

${ }^{2}$ Assistant Professor, Department of Urology, IGIMS.

${ }^{3}$ Student, Department of Urology, IGIMS.

${ }^{4}$ Student, Department of Urology, IGIMS.

5 Professor, Department of Urology, IGIMS.

ABSTRACT

A 44-year-old male presented with ulcerative growth over dorsal penile shaft along with multiple urethrocutaneous fistula. A total penectomy, scrotal excision and perineal urethrostomy were done. Past history of treatment for penile urethral stricture due to Balanitis Xerotica Obliterans (BXO) by substitution urethroplasty using pedicled preputial penile skin flap five years back. On gross as well as histopathological examination, the tumour was found to be arising from the skin flap used for substitution. This case highlights the malignant potential of skin affected by BXO and is probably the only case report where a skin flap has turned malignant.

\section{KEYWORDS}

Balanitis Xerotica Obliterans (BXO), Squamous Cell Carcinoma (SCC), Substitution Urethroplasty.

HOW TO CITE THIS ARTICLE: Singh RP, Mahmood K, Gunjan K, et al. A rare case report of squamous cell carcinoma of urethra arising from substituted penile skin flap with balanitis xerotica obliterans. J. Evolution Med. Dent. Sci. 2016;5(48):3110-3111, D0I: $10.14260 /$ jemds/2016/722

\section{INTRODUCTION \\ Lichen Sclerosis (LS) or Balanitis Xerotica Obliterans (BXO) is a chronic inflammatory skin disease of unknown origin with pathogenesis not completely known. The incidence is 1 in 300 to 1 in 1000.[1] BXO is found in all age groups, both sexes, more \\ secondaries. Total penectomy, scrotal excision with bilateral implant of testes on thigh and perineal urethrostomy was done. Histopathology of resected specimen showed squamous cell carcinoma grade 2 . The patient is asymptomatic and voiding well till last follow-up.} common in 30 to 50-year-male, characterised by dry, greyish white discoloration of prepuce, meatus and urethra along with pruritus and desquamation. Diagnosis of BXO is based on Histopathological (HPE) Examination.

There is a well-documented association between Lichen Sclerosus (LS) and vulvar carcinoma in women and the patients are asked to undergo regular surveillance. In males till recently the association was based on case reports, but recent studies show $5.8 \%{ }^{2}-8.4 \%{ }^{3}$ association of SCC in BXO patients.

\section{CASE HISTORY}

A 44-year-old male presented with ulcerative growth of approximate size $6 \mathrm{~cm} \mathrm{x} 4 \mathrm{~cm}$ over dorsal penile shaft along with multiple urethrocutaneous fistula [Figure 1]. There were multiple sinus tracts over scrotum filled with pus along with bilateral enlarged, mobile, non-tender inguinal nodes. The past history was significant for BXO affecting meatus, glans and penile urethra. The penile stricture required a substitution urethroplasty with preputial skin flap about five years back. Biopsy from growth revealed squamous cell carcinoma grade 2. A meatal biopsy was taken that revealed BXO, but no malignant change consistent with the previous biopsy reports done five years back. Bilateral FNAC was done and found to have non-specific lymphadenitis. Metastatic workup with CECT (Abdomen+Pelvis) and chest X-ray was negative for

Financial or Other, Competing Interest: None.

Submission 30-04-2016, Peer Review 24-05-2016,

Acceptance 30-05-2016, Published 16-06-2016.

Corresponding Author:

Dr. Rana Pratap Singh,

Lane 1 b, Shivpuram,

Vijaynagar, Rukunpura,

Patna, Bihar.

E-mail: ranapratapsingh02@gmail.com

DOI: $10.14260 /$ jemds/2016/722

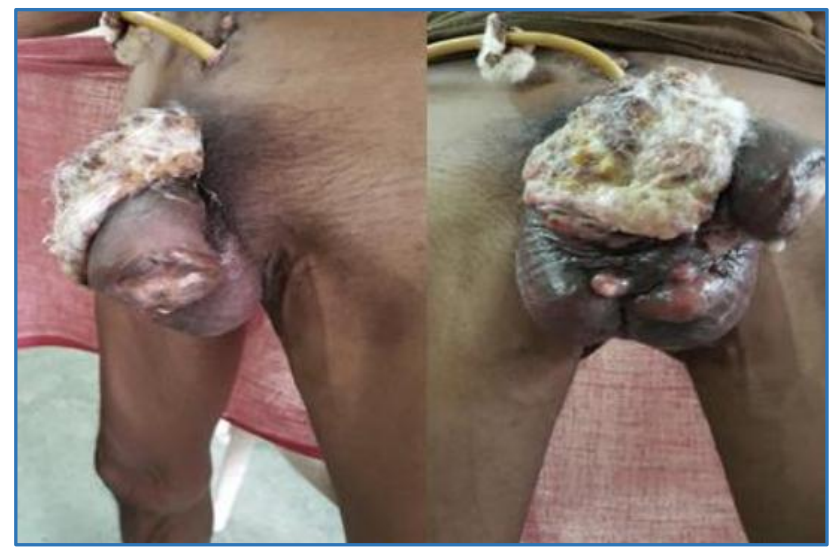

Fig. 1: Patients with Penile Growth, Overlying Ulcer and BXO Changes in Meatus and Glans

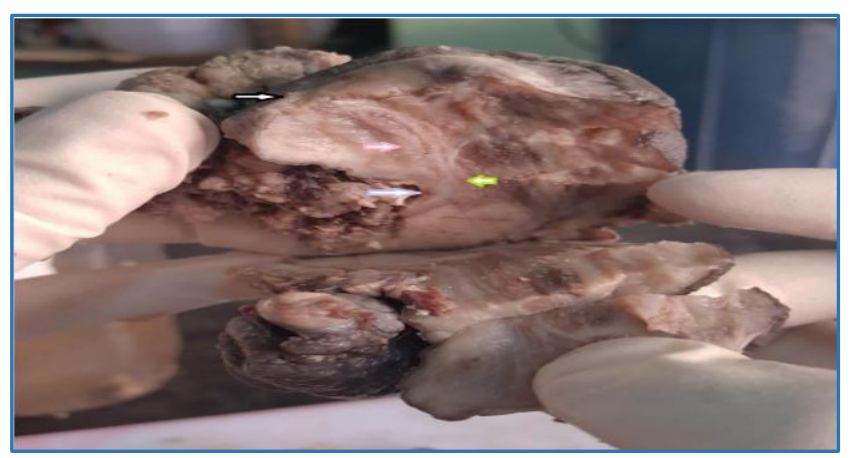

Fig. 2: Cut Surface showing Urethral Meatus Black Arrow, Strictured Urethral Plate Pink Arrow, Substituted Urethral Skin Area Green Arrow, Growth Arising from the Substituted Part Purple Arrow 


\section{DISCUSSION}

BXO is mainly known for its debilitating course and chronicity to urologist, which progressively involves urethra starting from glans along with surrounding skin to bulb.

For distal urethral involvement meatotomy or extended meatotomy is done, but at times whole anterior urethra is involved mandating some sort of reconstruction generally in the form of graft/flap or urethroplasty. The recommendation is to use skin uninvolved with disease process or less likely to be involved in disease process. ${ }^{4}$ such as buccal mucosal graft. But in avid tobacco chewers whole oral mucosa is unusable in such cases, skin flaps are only options available, but these skin flaps are always at the risk of getting involved with the disease process leading to poor urethroplasty outcomes. In this case, a substitution urethroplasty with preputial skin flap was done because of buccal mucosa being unusable.

The patient was advised to undergo strict surveillance protocols mainly to rule out recurrent strictures, but the patient never returned for follow-up and continued tobacco chewing, only to return after five years with this huge growth on the proximal shaft. A suprapubic cystostomy was done for diverting the urine and biopsies from the meatal opening showed BXO with no evidence of malignancy, while biopsies from the growth showed grade 2 SCC.

BXO is a known premalignant condition and a high association with SCC reported, most of the malignant conversions have been shown to be around glans where the disease process usually starts.

The proximal penile shaft is itself a rare site for the development of penile malignancy $<2 \% .^{5}$ In this case, the cut section revealed the tumour arising from the dorsolateral penile urethra the site of previous substitution [Figure 2], an extensive histopathological examination of the tumour and surrounding tissue was done, but no native urethral lining tissue was seen.

In this case probably amalgamation of factors worked in converting the skin flap malignant, the premalignant potential of BXO with recurrent bouts of infection and continued use of tobacco. The multiple urethrocutaneous fistulas were as a result of continued high pressure voiding and abscess formation, which burst through the skin allowing egress of urine so that the patient was able to pass urine for so long.

This case report being unique because of rarity of such kind of lesions and attests to the premalignant potential of BXO involved skin, mandating a strict follow-up schedule, so that early malignant changes if any could be detected.

\section{REFERENCES}

1. Wallace HJ. Lichen sclerosus et atrophicus. Trans St Johns Hosp Dermatol Soc 1971;57(1):9-30.

2. Nasca MR, Innocenzi D, Micali G. Penile cancer among patients with genital lichen sclerosus. J Am Acad Dermatol 1999;41(6):911-4.

3. Barbagli G, Palminteri E, Mirri F, et al. Penile carcinoma in patients with genital lichen sclerosus: multicenter survey. J Urol 2006;175(4):1359-63.

4. Venn SN, Mundy AR. Urethroplasty for balanitis xerotica obliterans. Br J Urol 1998;81(5):735-7.

5. Sufrin G, Huben R. Benign and malignant lesions of the penis. In Gillewater JY (ed.) Adult and paediatric urology, Chicago medical publisher 1991;1643-62. 